\title{
An Estimation of Different Minimum Exergy Return Ratios Required for Society
}

\author{
Victor Court ${ }^{1,2}$ (-)
}

Received: 12 March 2019 / Revised: 17 June 2019 / Accepted: 20 June 2019 / Published online: 2 July 2019

(c) The Author(s) 2019

\begin{abstract}
This article shows that as technical change enhances the conversion efficiency of primary-to-final and final-to-useful exergy processes, the minimum exergy return ratios (ExRR) required for society decreases, irrespective of the boundary under consideration. Therefore, the gains in exergy conversion efficiency that mostly occurred between the 1940s and the 1970s have compensated for the concurrent decrease of exergy surpluses of the fossil energy system. However, while the minimum ExRR required for modern societies have been quite stable since the 1970s, actual ExRR prevailing for energy systems have continued to decrease. Therefore, the increased difficulty in improving exergy conversion efficiency since the mid-1970s has resulted in a tightening exergy constraint on economic growth; this could partially explain the global economic slowdown of the last forty years. Further work is needed to estimate actual exergy return ratios that prevailed in the past decades and compare their distance relatively to the minimum levels estimated in the present article, and hence have a more precise idea of the exergy constraint's magnitude acting on economic growth.
\end{abstract}

Keywords Minimum ExRR · Exergy · Thermodynamic efficiency · Growth constraint

JEL Classification N50 $\cdot$ Q43 · Q55 - Q57

\section{Introduction}

The concept of energy-return-on-energy-investment (EROEI, or more simply EROI) of human societies has been the subject of much research since its formulation in the 1970s (Dupont et al. 2018; King and van den Bergh 2018; Hall 2017; Masnadi et al. 2018; Court and Fizaine 2017). The EROI is the ratio of the quantity of energy delivered by a given process to the quantity of energy consumed in that same process; it measures the accessibility of a resource-the higher the EROI, the greater the amount of net energy delivered to society that can support tasks other than energy extraction necessary for economic growth (Hall et al. 2014). Several scholars, such as King (2014) and Brandt

Victor Court

v.court@sussex.ac.uk

1 Science Policy Research Unit (SPRU), Business School, University of Sussex, Jubilee Building, Brighton BN1 9SL, UK

2 Chair Energy \& Prosperity, Institut Louis Bachelier, 28 place de la Bourse, 75002 Paris, France et al. (2013), point out that this definition is rather 'lose' nd that a clear distinction should be made between gross energy return ratio (GERR, i.e., the gross energy output divided by the energy consumed due to supply of final invested energy) and net energy return ratios (NERR, i.e., the energy that only goes to final consumption divided by the energy consumed due to supply of final invested energy). ${ }^{1}$ For the remainder of this article, we avoid the term EROI, and use ERR only when the distinction between GERR and NERR is either unnecessary or unclear when citing other studies.

\footnotetext{
${ }^{1}$ Moreover, King et al. (2015) show that another crucial distinction should be made between the 'early ERR' of an energy system (i.e., annual energy production divided by annual invested energy) and the 'full ERR' of the entire life cycle of an energy system (i.e., cumulated energy production divided by total life cycle invested energy). Understandably, the 'full ERR' represents the entire life cycle integral of all 'early ERRs' for a given energy system. These controversies surrounding ERR calculations are the subject of other articles (Murphy et al. 2011; Brandt et al. 2013; Modahl et al. 2013; Zhang and Colosi 2013; King 2014; Arvesen and Hertwich 2015).
} 


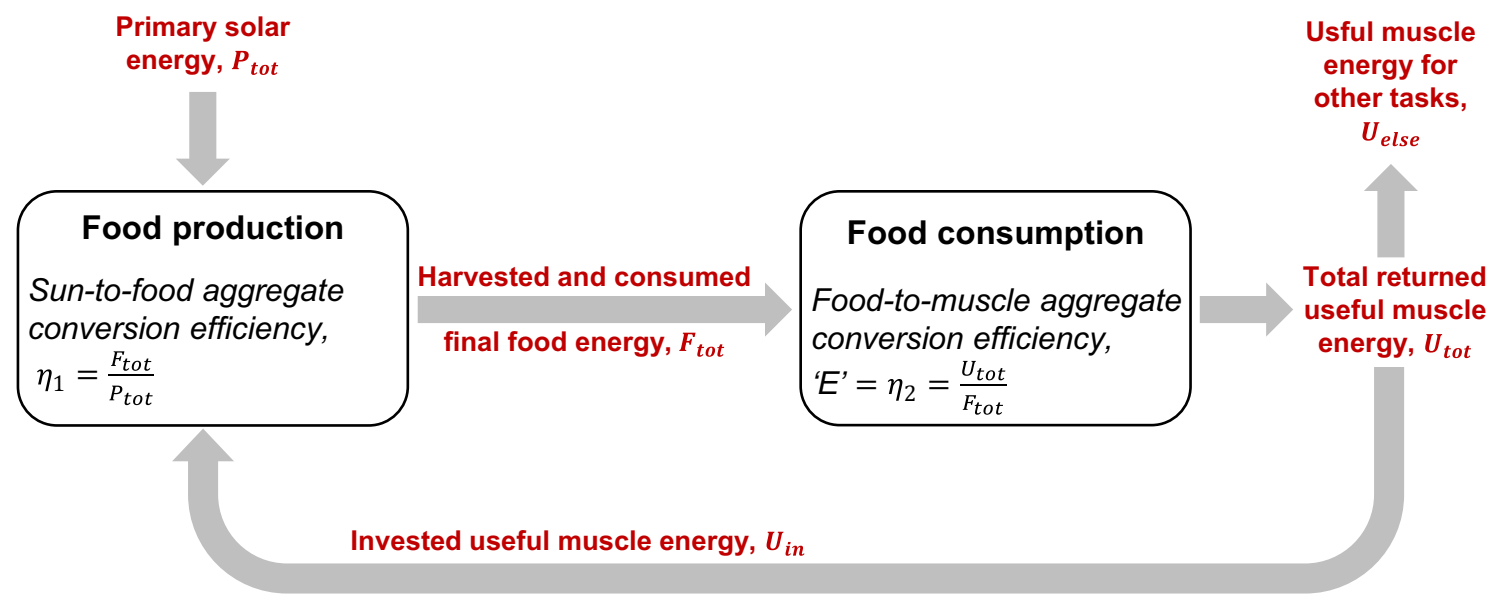

Fig. 1 Representation of the agrarian society described by Debeir et al.(2013, pp. 51, 52). For graphical convenience, losses at each stage are not represented. Source author

\section{A Link Between the Minimum Energy Return Ratio of Society and Its Energy Conversion Efficiency}

Debeir et al. (2013) describe a simple link between the minimum ERR required for society and its aggregate energy conversion efficiency. ${ }^{2}$ Below is a personal translation of this statement, from pages 51 to 52, in the context of agrarian societies.

'In terms of energy, society 'invests' a certain energy quantity and 'harvests' a given food-energy quantity, obviously greater than the initially invested energy. Hence, the ratio

$P=\frac{\text { Harvested energy }}{\text { Invested energy }}$

measures the energy productivity of society. For its part, the population returns to the biosphere a fraction of this consumed food energy in the form of work. The efficiency of such a conversion is measured by the following ratio:

$E=\frac{\text { Returned energy }}{\text { Consumed energy }}$

[...] Every society must comply with the following: the energy conversion efficiency must be at least the inverse of the energy productivity of the food production system. If we take the cycle: subsistence $\rightarrow$ human energy $\rightarrow$ subsistence, and with the example of a society in which the conversion efficiency would be

\footnotetext{
${ }^{2}$ For an English translation of the 1986 French first edition, see
} Debeir et al. (1991).
$E=5 / 100$, meaning that, when this society has 100 kilocalories of subsistence, it cannot re-invest more than 5 kilocalories in its predatory or productive activities. To enable this society to at least simply reproduce, the energetic productivity $P$ must be greater than $100 / 5$, otherwise the energy potentially re-invested in the next cycle will not be capable of supplying enough subsistence for the needs of society. This reproduction condition is expressed by the following general inequality:

$P>\frac{1}{E} \cdot{ }^{\prime \prime}$

One might argue for the unclear definition of the different concepts used in the above quotation from Debeir et al. (2013, pp. 51, 52). Indeed, as shown in Fig. 1, 'harvested' and 'consumed' energy correspond to final food energy generated by the photosynthetic conversion of primary solar energy; whereas 'invested' and 'returned' energy correspond to useful muscle energy resulting from the human body conversion of final food energy. ${ }^{3}$ So, to be clear, the 'energy productivity $P$ ', described by Debeir et al. (2013, pp. 51, 52) in the context of an agrarian society, corresponds to the gross quantity of final food energy that society is able to generate per unit of invested useful muscle energy; in other words, it corresponds to the $G E R R_{F / U}=\frac{F_{\text {tot }}}{U_{\text {in }}}$ of society. ${ }^{4}$

\footnotetext{
${ }^{3}$ In the quotation of Debeir et al. (2013, pp. 51, 52), it is unclear if the quantity of 'consumed' food energy is lower than the 'harvested' quantity because of losses during food processing. In the absence of greater precision, we assume in Fig. 1 that these processing losses are not taken into account and that, consequently, harvested and consumed food quantities are strictly equal.

${ }^{4}$ For the purpose of consistency, it is noted that the useful energy invested in food production, $U_{i n}$, includes not only to the muscle work directly exerted to complete agricultural duties, but also the muscle
} 
Moreover, in the context of agrarian societies, the energy 'conversion efficiency $E$ ' of Debeir et al. (2013, pp. 51, 52) corresponds to the aggregate efficiency of humans and draft animals to convert final food energy into muscle useful work, i.e., $E=\frac{U_{t o t}}{F_{t o t}}=\frac{U_{e s s}+U_{i n}}{F_{t o t}}$. This final-to-useful energy conversion efficiency is conventionally described as $\eta_{2}$, while, as shown in Fig. 1, $\eta_{1}$ would designate the primaryto-final efficiency of the sun-to-food energy conversion process. Finally, one can reformulate the last relation of the above quotation of Debeir et al. (2013, pp. 51, 52) as follows: the minimum gross energy return ratio of an agrarian society is equal to the inverse of its final-to-useful energy conversion efficiency, i.e., GERR $R_{\min , F / U} \equiv\left(\frac{F_{t o t}}{U_{\text {in }}}\right)_{\min }=\frac{1}{\eta_{2}}$.

\section{Goal and Organization of the Paper}

It appears that there is no definition or estimation of the minimum societal requirement ERR that uses Debeir et al.'s (2013, pp. 51, 52) analysis. Although this might appear surprising given the apparent simplicity of this relation, distinguishing conversion efficiency at different stages (primary, final, and useful) means that the minimum ERR required for society is dependent on the system boundary. Moreover, the exergy concept is perhaps a more appropriate concept than energy for assessing the biophysical dynamics of society

the possibilities of estimations for the different minimum exergy returns ratios. Nevertheless, "Result" section presents the long-run estimates of the minimum exergy return ratios of the European Union(EU)-15 countries, the USA, Japan, and the world. "Discussion" section discusses these results in the context of economic growth fluctuations and economic development levels. Finally, "Summary and Perspectives" section delivers the contributions and opportunities for future research.

\section{Methodology}

\section{Analytical Approach}

It is possible to systematize to all societies the analysis developed by Debeir et al. $(2013$, pp. 51, 52) in the special case of agrarian societies by drawing on the literature related to exergy (see Appendix A and B). Figure 2 is a graphical generalization of Fig. 1 in exergy terms. One can then theoretically compute three minimum gross exergy return societal requirement ratios $\left(G E x R R_{\min }\right)$ as shown in Fig. 2, namely

$G \operatorname{ExRR}_{\min , P / F}=\left(\frac{P_{\text {tot }}}{F_{\text {tot }}}\right)_{\min }=\frac{1}{\varepsilon_{1}}$,

$G \operatorname{ExRR}_{\min , F / U}=\left(\frac{F_{\text {tot }}}{U_{\text {direct,up }}+U_{\text {embodied,up }}+U_{\text {direct,down }}+U_{\text {embodied,down }}}\right)_{\min }=\frac{1}{\varepsilon_{2}}$,

$G \operatorname{ExRR}_{\min , P / U}=\left(\frac{P_{\text {tot }}}{U_{\text {direct,up }}+U_{\text {embodied,up }}+U_{\text {direct,down }}+U_{\text {embodied,down }}}\right)_{\min }=\frac{1}{\varepsilon}$.

[see Appendix A and the recent synthesis of Brockway et al. (2018)]. Accordingly, in exergy terms, primary-to-final, final-to-useful, and primary-to-useful conversion efficiency are respectively designated by $\varepsilon_{1}, \varepsilon_{2}$, and $\varepsilon$ (see Appendix B). Taking stock of these different concepts, this article seeks to reformulate Debeir et al. $(2013$, pp. 51, 52) in a more pragmatic way.

"Methodology" section shows that several minimum exergy return ratios (ExRR) can be computed in relation to different exergy conversion efficiencies. Data availability presented at the end of this methodological section restricts

Footnote 4 (continued)

energy used to produce the different tools and physical assets necessary for food production. In other words, $U_{\text {in }}$ is the sum of the direct and indirectly embodied energy investments in food production. where $G E x R R_{\min , P / F}$ gives the minimum number of primary exergy that the upstream energy sector must generate per unit of invested (direct + embodied) final exergy, $G E x R R_{\min , F / U}$ gives the minimum number of final exergy that the energy sector must return per unit of direct invested (direct + embodied) useful exergy, and $G E x R R_{\min , P / U}$ gives the minimum number of primary exergy that the upstream energy sector must yield per unit of invested (direct + embodied) useful exergy.

\section{Data}

Several time series have been computed for exergy conversion efficiency. ${ }^{5}$ Serrenho et al. (2014) estimate the

\footnotetext{
${ }^{5}$ On the contrary, as far as we know, even though energy is a more familiar concept than exergy, time series have never been estimated for energy conversion efficiency.
} 

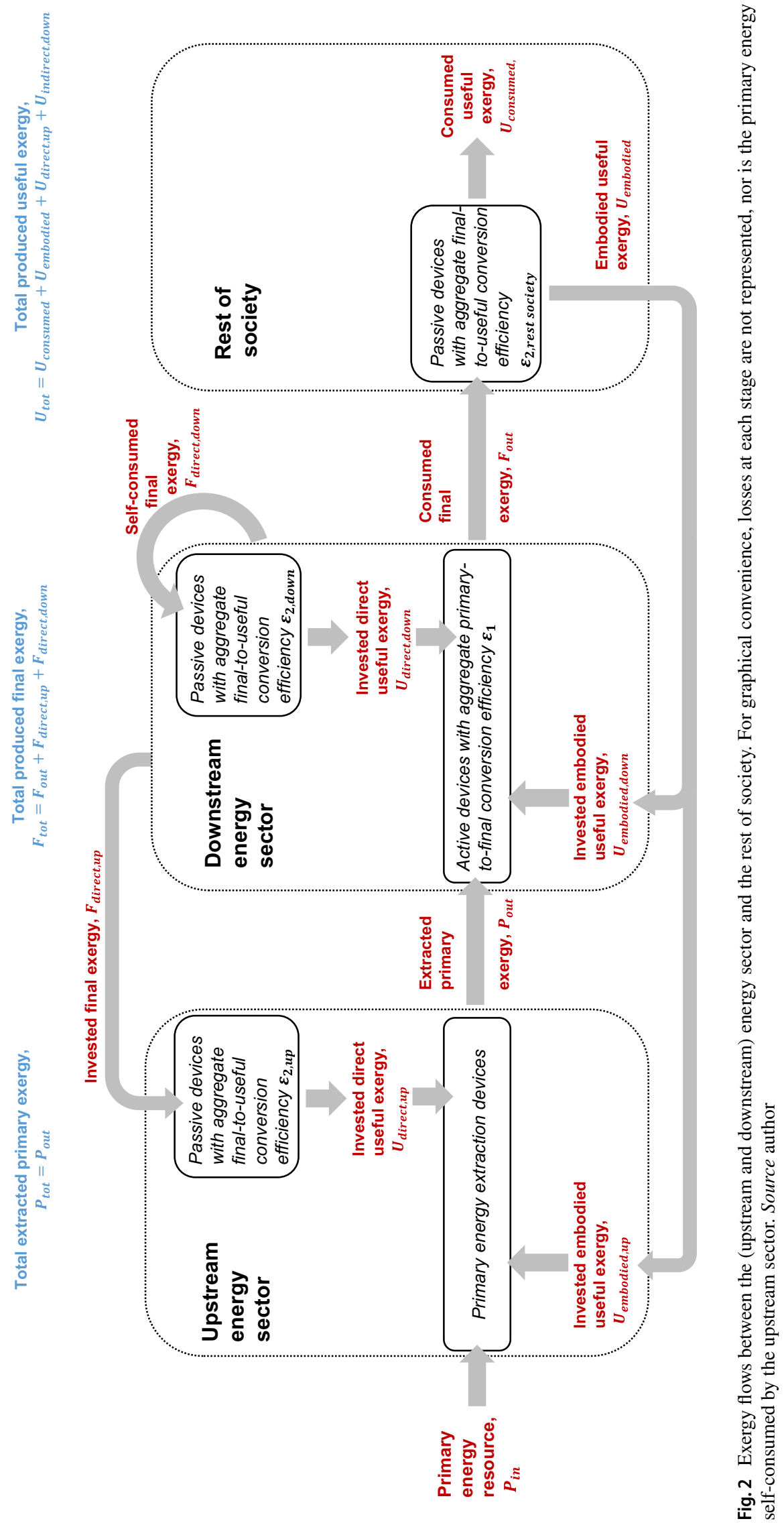

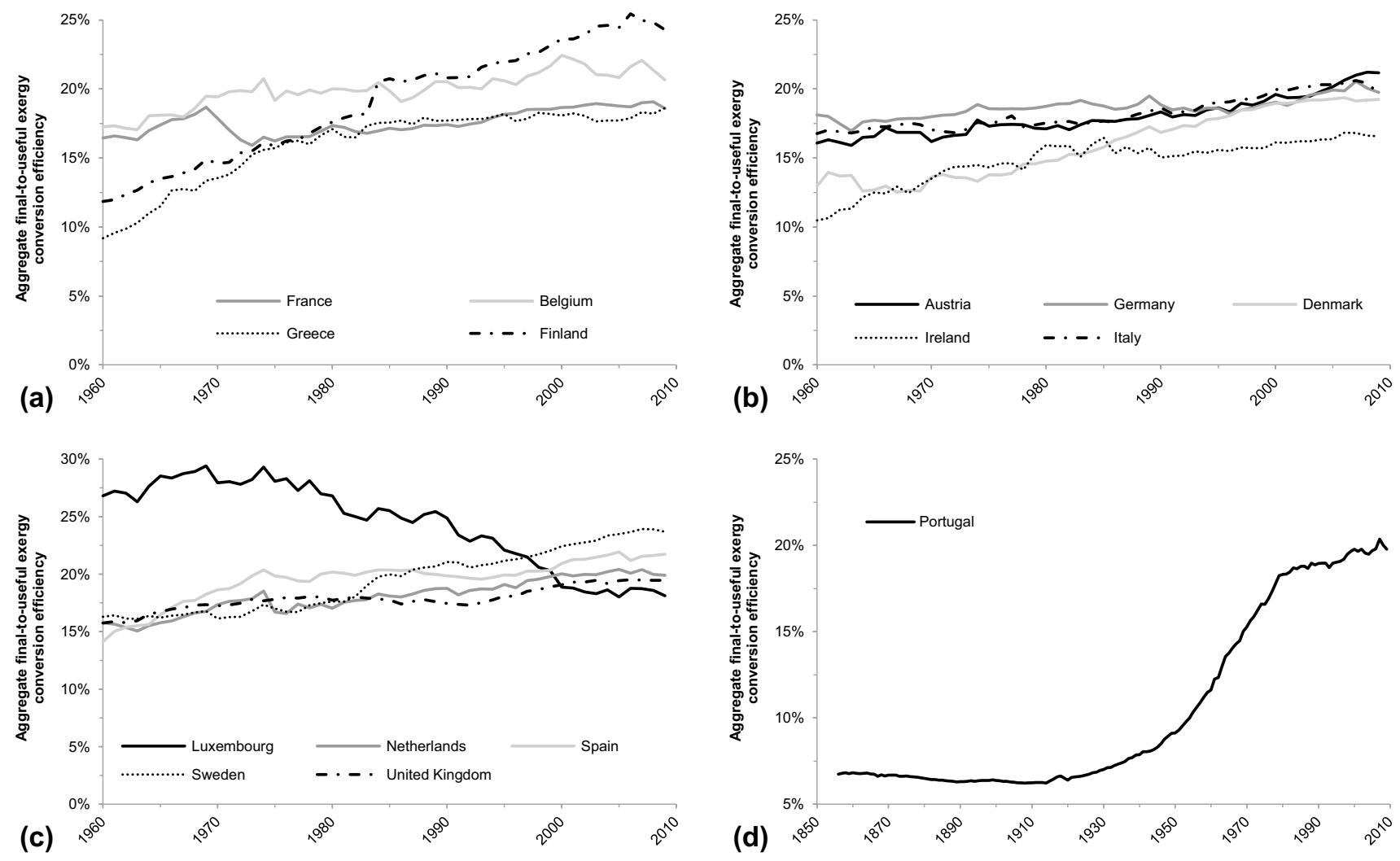

Fig. 3 Aggregate final-to-useful exergy conversion efficiency $\left(\varepsilon_{2}\right)$ of the EU-15 countries (1856-2009 for Portugal, 1960-2009 for all others). Source data from Serrenho et al. $(2014,2016)$

aggregate final-to-useful exergy efficiency $\left(\varepsilon_{2}\right)$ of the European Union(EU)-15 countries from 1960 to 2009, and these authors have extended this analysis up to 1856 for Portugal (Serrenho et al. 2016) (Fig. 3).

Warr et al. (2010) estimated the aggregate primary-touseful exergy conversion efficiency $(\varepsilon)$ for the USA, UK, Austria, and Japan from 1900 to 2000 and updated Austria's 1900 to 2012 values in Eisenmenger et al. (2017). Brockway et al. (2014) also updated the US and UK primary-touseful exergy conversion efficiency values $(\varepsilon)$ from 1960 to 2010. Despite several differences in methodologies, ${ }^{6}$ we used Brockway et al. (2014)'s trends to extend Warr et al. (2010)'s data for the USA and UK from 2000 to 2010. De

\footnotetext{
${ }^{6}$ Differences correspond to (i) the fact that Brockway et al. (2014) only take into account the above-basal-need food intake needed for heavy labor, while Warr et al. (2010) consider the entire food intake of people; (ii) a higher assumption for food conversion efficiency into muscle work in Brockway et al. (2014) compared to Warr et al. (2010; (iii) a higher mechanical drive efficiency in Brockway et al. (2014) compared to that from Warr et al. (2010) (e.g., 11\% vs $8 \%$ respectively in 1960); and (iv) a higher heat efficiency in Brockway et al. (2014) as more heat is allocated to Low Temperature Heat enduse in Warr et al. (2010)'s analysis (e.g., 12\% vs 7\% respectively in 1960).
}

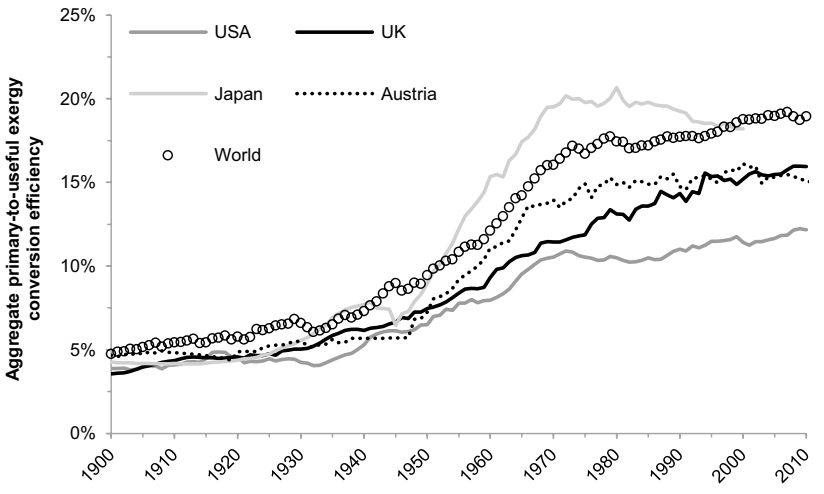

Fig. 4 Aggregate primary-to-useful exergy conversion efficiency $(\varepsilon)$ of the USA (1900-2010), UK (1900-2010), Austria (1900-2012), Japan (1900-2000), and the world (1900-2014). Source data from Warr et al. (2010), Brockway et al. (2014), De Stercke (2014) and Eisenmenger et al. (2017)

Stercke (2014) performed the same assessment of the aggregate primary-to-useful exergy conversion efficiency $(\varepsilon)$ for the world economy from 1900 to 2014 (Fig. 4).

Brockway et al. (2015) estimated China's primary-touseful exergy conversion efficiency $(\varepsilon)$ between 1971 to 2010 using a similar methodology to Brockway et al. (2014). 

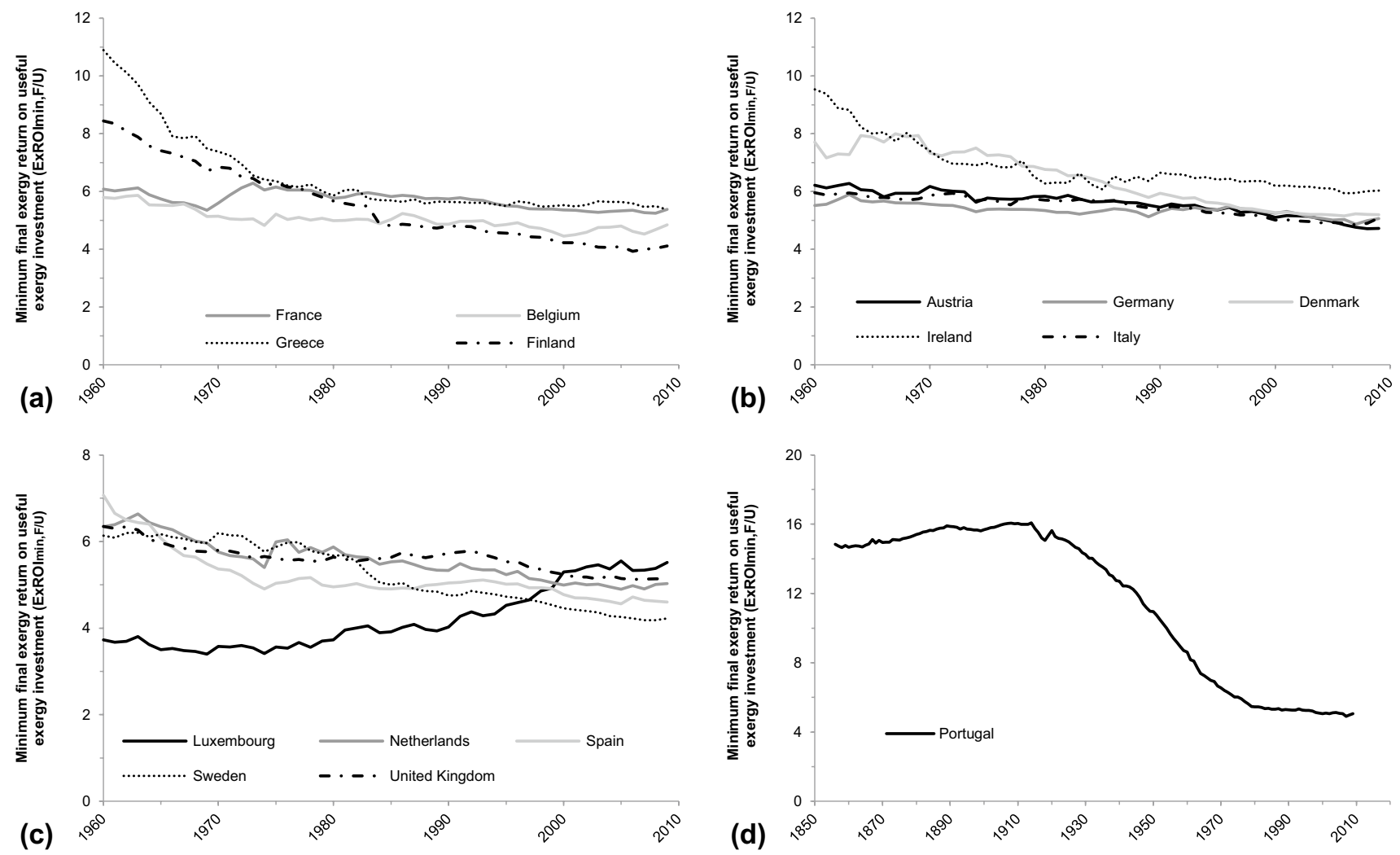

Fig. 5 Minimum final exergy return on useful exergy investment $\left(G E x R R_{\min , F / U}\right)$ of the EU-15 countries (1856-2009 for Portugal, 1960-2009 for all others). Source author's computation

We chose not to show these data on Fig. 4 for the sake of methodological consistency. Serrenho et al. (2016) and De Stercke (2014) also determined the primary-to-final exergy conversion efficiency $\left(\varepsilon_{1}\right)$ for Portugal (1856-2009) and the world economy (1900-2014) respectively. Nevertheless, up to recent decades, these estimates are really close to unity because of the relative importance of food and feed (i.e., fodder for draft animals) whose primary energy estimates are conventionally equated entirely to final energy, meaning that the conversion efficiency of solar primary energy into final chemical energy of photosynthetic plants of around $4 \%$ is not accounted for. Hence, estimates of primary-to-final exergy conversion efficiency only make sense when nonfood energy forms are dominant.

\section{Results}

\section{Estimates of the GEXRR $R_{\min , F / U}$ of the EU-15 Countries}

Eq. (2) and data in Fig. 3 allowed the calculation of the $G_{\operatorname{ExR}} R_{\min , F / U}$ for the EU-15 countries. Portugal, with its data providing a long time-span, delivers the most

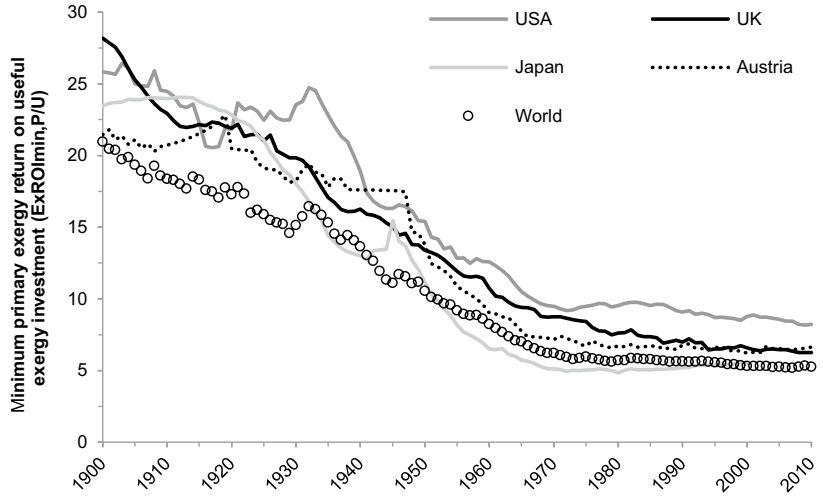

Fig. 6 Minimum primary exergy return on useful exergy investment $\left(G E x R R_{\min , P / U}\right)$ of the USA (1900-2010), UK (1900-2010), Austria (1900-2012), Japan (1900-2000), and the world (1900-2014). Source author's computation

interesting insight. Figure $5 \mathrm{~d}$ shows the consistency of Portugal's $G E x R R_{\min , F / U}$ from the 1850 s to the 1920 s at approximately 15-16. It then follows a decreasing sigmoid shape and declined towards a value of 5 . The results also show other countries follow a similar pattern from 1960 to 2009 with Luxembourg being a notable exception. One can 
observe this consistent decrease towards a minimum final exergy quantity of around 5 units that the energy sector of these countries must yield per unit of invested useful exergy.

\section{Estimates of the GExRR $R_{\min , P / U}$ of the USA, UK, Austria, Japan, and the World}

We can easily compute the $G E x R R_{\min , P / U}$ of the USA (1900-2010), UK (1900-2010), Austria (1900-2012), Japan (1900-2000), and the world (1900-2014) by combining Eq. (3) with the data presented in Fig. 4. Figure 6 shows that the minimum primary exergy yielded by USA, UK, Austria, and Japan per unit of invested useful exergy declined between 1900 and 2010s from about 25 to 6 following decreasing sigmoid-shape trends. The $G E x R R_{\min , P / U}$ for the world economy has a very similar sigmoid declining trend.

\section{Discussion}

\section{Comparison with Other Studies Providing a Minimum ERR Required for Society}

Four previous studies discuss potential values for minimum societal ERR. Hall et al. (2009) suggested a technical minimum ERR of 3 for oil at the well-head and 5 to support complex societies, but concluded that a minimum ERR around 12-15 for primary energy is probably necessary to sustain modern lifestyles. Weißbach et al. (2013) give a minimum ERR of 7 required for OECD countries although the underlying calculation is not provided. Lambert et al. (2014) used nonlinear correlations between ERR and the Human Development Index (HDI) in cross sectional data to claim that contemporary societies require a societal minimum ERR of 15 for primary energy to reach an HDI of at least 0.7. Finally, Fizaine and Court (2016) used an indirect approach based on energy expenditures to show that the USA required its primary energy to be supplied with a (yearly) GERR above 11 for economic growth. This econometric result indicates a GERR primary energy requirement of around 12-15 to support a growing modern economy. These four studies concern primary energy, and there is seemingly no study that estimates the final stage minimum ERR for society. However, two recent articles assessing the point of use return ratio of final energy for two different countries can provide some answers on this subject. Feng et al. (2018) estimated the NERR of China's final energy production sector declined from 11 to 5.5 between 1987 and 2012. Brockway et al. (2019) estimated that the NERR of fossil fuels at the final stage declined from 6 to 5.4 between 1995 and 2011 . These results suggest a minimum ERR requirement between approximately 4 and 5 for the final energy supply of industrialized societies.
Theoretically, the minimum ERR estimate of 11-15 should compare favorably with the $G E R R_{\min , P / F}=1 / \varepsilon_{1}$ of Eq. (1). Unfortunately, as stressed in subsection 2.2, the quality of current $\varepsilon_{1}$ estimates prevent a meaningful calculation of the $G E x R R_{\min , P / F}$. The $G E x R R_{\min , P / U}$ estimated in this article has a sufficiently different boundary that it prevents direct comparison with Hall et al. (2009), Weißbach et al. (2013), Lambert et al. (2014), and Fizaine and Court (2016). With the present methodology it is not possible to calculate a final stage energy minimum ERR that would correspond to the boundaries of Feng et al. and Brockway et al. (2019). Both Feng et al. and Brockway et al. (2019) estimate final energy return per final energy input unit, whereas the exergy output from Eq. (2) is also at the final stage but the exergy inputs at the denominator correspond to useful exergy.

\section{ERR Dynamics and Economic Growth}

There has been no attempt so far to calculate the 'real' exergy return ratio in the past for a given energy system or society. We cannot directly compare our 'minimum required' GExRR estimates from the previous section with real GExRR to assess societal exergy constraints. Nevertheless, our results suggest that as technical change enhances the conversion efficiency of primary-to-final and final-touseful en/exergy processes, the societal minimum E/ExRR decreases irrespective of the boundary under consideration (Figs. 5, 6). ${ }^{7}$ This could explain why the decline in GERR of oil and gas global productions identified by Court and Fizaine (2017) did not cause significant economic degrowth. In other words, improvements in en/exergy conversion efficiency between the 1940s and the 1970s (Figs. 3, 4) compensated for fossil energy system decreases in en/exergy surpluses, and allowed the global economy to grow at 3.0\% per year between 1950 and 1970 .

However, the rate of global economic growth slowed down after the 1970 s. ${ }^{8}$ Some may see this slowdown as a deficiency compared to the 1950-1970s time period; others may argue that we are reverting to the previous low growth trend. Either way, there is no consensus on what caused this global macroeconomic slowdown that is more apparent in more economically-developed countries compared to less economically-developed countries (Gordon 2015; Summers

\footnotetext{
7 The term E/ExRR is used in this section and in the conclusion when speaking about a return ratio without any distinction between energy and exergy. Accordingly, I'll also use the term $E / E x R R_{\text {min }}$ when speaking about the minimum E/ExRR required for society.

${ }^{8}$ Precisely, from 1970 to 1990 , the average annual growth rate of gross world product per capita was only $1.65 \%$ per year, and it slightly increased to $2.3 \%$ during the 1990-2010 period, before slightly decreasing again to $2.0 \%$ between 2010 and 2016. [All growth rates estimates are derived from the gross world product per capita of Bolt et al. (2018)]
} 
2015). That greater efficiencies in en/exergy conversion have been harder to get since the mid-1970s (see Figs. 3, 4) could account for this global economic slowdown. While the minimum E/ExRR required for modern societies have been stable since the mid-1970s (Figs. 5, 6), actual E/ExRR prevailing for energy systems have decreased worldwide (Court and Fizaine 2017; Masnadi et al. 2018). This could have caused a tightening exergy constraint on economic growth. Further work is needed to estimate the actual exergy return ratios in that period to determine the validity of this hypothesis. Confirming whether actual ExRR decreased over this period would reinforce the high level of correlation between annual gains in the UK and Ghana's aggregate exergy conversion efficiency and economic growth identified by Heun and Brockway (2019).

Finally, it is worth pointing out that the historical slowing down in exergy efficiency improvements are due to (i) the limits reached in thermal processes that are physically constrained by the Carnot limit, and (ii) the increasing prevalence of less efficient processes, such as air-conditioning, particularly in most economically-developed countries (Brockway et al. (2014) refer to this phenomenon as a 'dilution effect'). Significant opportunities for exergy efficiency improvements exist at the end-use stage. One could therefore expect that future increases in aggregate exergy conversion efficiency would decrease the societal requirements for exergy return ratios. This could alleviate the net en/xergy constraint of society. But using currently untapped efficiency improvements would not necessarily mitigate the global energy resource and climate change dilemmas because of different and potentially large rebound effects [see Broberg et al. (2015), Brockway et al. (2017), and Bye et al. (2018)].

\section{A Possible Correlation Between the Useful Exergy Return on Useful Exergy Investment of Society and Levels of Economic Development}

Return ratios analyses based on exergy could overcome the problem posed by the absence of a correlation between the aggregate ERR of society and its level of economic development when comparing foraging, agrarian, and industrial societies. It is clear that one cannot directly relate higher levels of economic development with higher ERR because foraging and traditional farming societies can present similar ERR values to modern industrial societies. For instance, Smil $(2017$, pp. 36, 37) claimed that foraging societies have typical gathering returns around 10-20 final food-energy units per useful muscle-energy unit invested, similar to those of hunting large animals. Similarly, Smil (2017, pp. 44, 45 ) reported that many early agricultural societies yielded 15-20 final food-energy units per unit of useful muscleenergy investment. We could postulate that the overall level

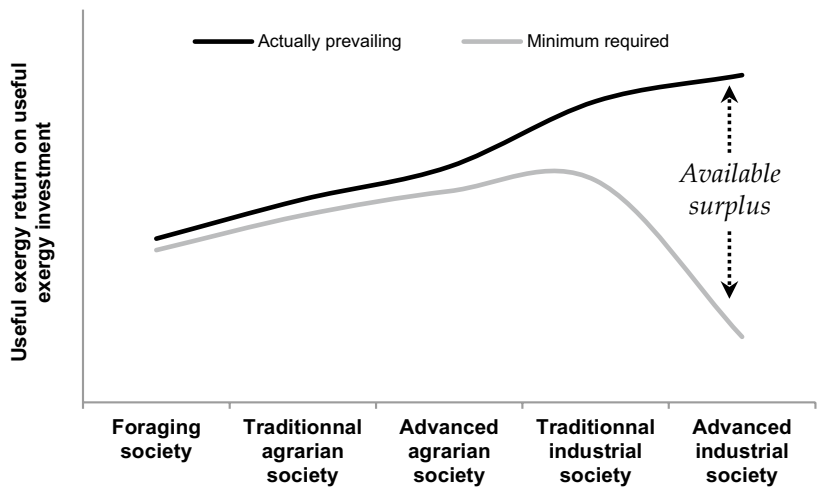

Fig. 7 Hypothetical evolutions of actually prevailing and minimum required useful exergy return on useful exergy investment. Source author (the curves are purely hypothetical and do not correspond to empirical data)

of economic development of a society is correlated with the discrepancy between the 'actually prevailing' and 'minimum required' useful exergy return on useful exergy investment of its energy system. This is visually represented in Fig. 7. Such a gap between required and prevailing useful exergy return per invested unit of useful exergy would correspond to an 'available surplus of useful exergy' that could act as a good proxy for the level of economic development. Further research is still needed to confirm this proposition.

\section{Summary and Perspectives}

This article drew upon a concept devised by Debeir et al. (2013, pp. 51, 52) to show that several minimum exergy returns ratios can be calculated in relation to different levels of exergy conversion efficiency. Current data availability restricts estimation possibilities to the $G E x R R_{\min , F / U}$ of the European Union(EU)-15 countries, and the $G E x R R_{\min , P / U}$ of the USA, UK, Austria, Japan, and the world. Our results indicate a consistent sigmoid-shaped decline for all these minimum gross ExRR. Our methodology and the resulting $G E / E x R R_{\min }$ estimates suggest that, as technical change enhances the conversion efficiency of primary-to-final and final-to-useful exergy processes, the minimum ExRR required for society decreases irrespective of the boundary under consideration.

We discussed those estimates in relation to previous ERR studies. It appears that improvements in exergy conversion efficiency between the 1940s and the 1970s compensated for concurrent decreasing exergy surpluses of the fossil energy system. However after this period, while the minimum modern society ExRR requirement has stabilized, actual ExRR prevailing for energy systems have continue to globally decrease. This decrease in the growth of exergy conversion 
efficiency since the mid-1970s could have constrained economic growth and could partly explain the global economic slowdown of the last 40 years.

Overall, this article indicates that analyses of return ratios based on exergy and not energy might deliver more insightful outcomes compared to standard economic indicators such as GDP growth rates. Therefore, greater attention and investment should be directed toward estimating the final or useful exergy returns on useful exergy investment of energy systems. The calculation of such exergy return ratios would give a more precise understand of the effect of the exergy constraint on economic growth.

Acknowledgements This work benefited from the support of the Chair Energy\& Prosperity. I thank Paul Brockway for his helpful comments on an earlier version of this article. I am also grateful to two anonymous referees for their fruitful comments and suggestions. Many thanks to David Eggleton for correcting the spelling and grammar of this text. All remaining errors are mine.

\section{Compliance with Ethical Standards}

Conflict of interest The author declares that he has no competing interests.

Open Access This article is distributed under the terms of the Creative Commons Attribution 4.0 International License (http://creativeco mmons.org/licenses/by/4.0/), which permits unrestricted use, distribution, and reproduction in any medium, provided you give appropriate credit to the original author(s) and the source, provide a link to the Creative Commons license, and indicate if changes were made.

\section{Appendices}

\section{Appendix A: Energy Versus Exergy}

Energy, measured in joule $(\mathrm{J})$ is a principle concept in thermodynamics that is formally defined as the ability of a system to cause change. ${ }^{9}$ In practice, energy is rarely considered in terms of its content but rather in terms of its flow: thermal energy flows from a body to another, this is also the case for chemical energy, mechanical energy, electrical energy, and so on (Sciubba 2011).

\footnotetext{
$\overline{9}$ One joule $(\mathrm{J})$ is defined as the quantity of work transferred to an object by moving it a distance of one meter $(\mathrm{m})$ against a force of one newton $(\mathrm{N})$, i.e., $1 \mathrm{~J}=1 \mathrm{Nm}$. One newton is the force needed to accelerate one kilogram $(\mathrm{kg})$ of mass at the rate of one meter per second (s) squared in the direction of the applied force, i.e., $1 \mathrm{~N}=1 \mathrm{~kg} \mathrm{~ms}^{-2}$. In the context of energy transfer as heat, $1 \mathrm{~J}=0.2389$ calorie, and one calorie represents the energy needed to raise the temperature of one gram of water by one degree Celsius at a pressure of one standard atmosphere (corresponding to 101,325 Pascal).
}

Table 1 Exergy factor for primary and final energy carriers. Source adapted from Serrenho et al. (2016)

\begin{tabular}{ll}
\hline Primary energy source or final carrier & $\begin{array}{l}\text { Primary }\left(\Phi_{P}\right) \text { or final } \\
\left(\Phi_{F}\right) \text { exergy factor }\end{array}$ \\
\hline Coal and coal products & 1.06 \\
Oil and oil products & 1.06 \\
Natural gas and gas products & 1.04 \\
Renewable combustibles (biomass) & 1.11 \\
Food and feed & 1.00 \\
Other non-conventional & 1.00 \\
Electricity & 1.00 \\
Heat from Combined Heat \& Power (CHP) & 0.60 \\
plant & \\
\hline
\end{tabular}

However, energy is not sufficient to understand real processes because real processes vary in both quantity and quality. From the beginning of the Industrial Revolution, scientists and entrepreneurs noticed that the fraction of energy that can be converted into 'useful' mechanical work is not the same from one process to another. Scientists introduced the concept of exergy to account for the capacity of a given quantity of energy to be converted into mechanical work. Exergy (also measured in joule) is formally the maximum amount of work that can be recovered from a system as it approaches equilibrium with its surroundings (Ayres 1998). ${ }^{10}$ The physical quality of a given quantity of energy changes according to its relative exergy content.

Exergy derives from the second law of thermodynamics, which states that every transformation process involves the loss of some quality of the system because of physical constraints at the microscale and are visible as friction and heat loss at the macroscale. In other words, exergy is destroyed in any conversion process as energy flows lose their ability to perform work (Kümmel 2011, p.114). On the other hand, energy is conserved in every process and cannot be destroyed as stipulated by the first law of thermodynamics (Miller et al. 2016).

Therefore, calculating an exergy value from an energy value depends on the efficiency of the process under consideration. In most energy calculations, energy is often described as fuel, electricity, mechanical work, heat, or non-energy products. As summarized in Table 1, for each form the exergy content is different (Serrenho et al. 2016). Fuels have exergy factors (the ratio of exergy to energy) greater than 1 because their theoretical maximum work

\footnotetext{
${ }^{10}$ Earlier equivalent terms to name exergy are available work, available energy (or even availability), and free energy. For the sake of completeness and clarity, 'Gibbs free energy' represents exergy in a particular process performed at constant temperature and pressure, whereas 'Helmholtz free energy' represents exergy in a particular process performed at constant temperature and volume.
} 
Table 2 Exergy content of different energy flows $\left(T_{0}\right.$ is the environment temperature and $T$ is the temperature of the reservoir from which heat is added)

\begin{tabular}{|c|c|c|}
\hline Energy flow $(E)$ & Exergy content $(E x)$ & Observations \\
\hline Fuel & $E x=-\Delta G=|\Delta H|-T_{0} \Delta S$ & $\begin{array}{l}\text { The maximum work done by a fuel is the chemical work of its combustion corresponding to the } \\
\text { released Gibbs free energy, }-\Delta G \text {, equals to: the enthalpy of combustion, } \Delta H \text {, minus the heat, } \\
T_{0} \Delta S \text {, rejected as a consequence of the entropy received }\end{array}$ \\
\hline Electricity & $E x=E$ & Electricity can be completely converted to work \\
\hline Work & $E x=E$ & Available work is exergy by definition \\
\hline Heat & $E x=E\left(1-\frac{T_{0}}{T}\right)$ & $\begin{array}{l}\text { The maximum work done by a heat flow is the work that would be done by a Carnot cycle work- } \\
\text { ing between } T \text { and } T_{0}\end{array}$ \\
\hline
\end{tabular}

Source adapted from Serrenho et al. (2016)

content correspond to their standard enthalpy of combustion $(\Delta H)$ plus the additional contribution of the postcombustion water vapor (lower heating value) and the flue-gas components (Table 2, row 1). Mechanical (both kinetic and potential) and electric energy flows can be completely converted to useful work. They have an exergy factor of 1 , while in the case of work that produces some sort of waste such as heat, the exergy factor is less than 1 . Therefore electrical energy can be completely converted to work and its exergy content equals its energy (Table 2, row 2$),{ }^{11}$ while heat cannot be completely converted into work. In this case, the maximum work extractable from a sub-system connected to a thermal reservoir at $T_{0}$ is the work obtained by an ideal Carnot engine (Table 2, row 4).

\section{Appendix B: Energy Versus Exergy Conversion Efficiency}

Primary $P$ energy and exergy are present in the environment in the form of $i$ natural stocks (coal, oil, gas, and uranium) or flows (sun, water, wind, geothermal source, wave, and tide). Primary en/exergy (a term used from now on when speaking without distinction of energy and exergy) forms are of no use for humans so that conversions of those primary resources into $j \geq i$ secondary en/exergy types are required. Such final $F$ en/exergy carriers consist in refined products of solid, liquid or gaseous forms, electricity, and heat flows. A number of $k \geq j \geq i$ end-use devices allow the conversion of final carriers into useful $U$ en/exergy in the form of motion (i.e., mechanical drive), heat, and light, and electricity for information processing. ${ }^{12}$ One can compare the conversion efficiency of individual processes from either an energy or exergy approach (Fig. 8).

Energy conversion efficiency, also called first-law efficiency, expresses the fraction of 'useful' energy transferred in a process. Hence, for any $j$ primary-to-final process and any $k$ final-to-useful device, one can respectively define:

$\eta_{1, j}=\frac{\text { final energy output, } j}{\text { primary energy input, } i}=\frac{E_{\text {out }, F, j}}{E_{\mathrm{in}, P, i}}$

and,

$\eta_{2, k}=\frac{\text { useful energy output, } k}{\text { final energy input, } j}=\frac{E_{\text {out }, U, k}}{E_{\mathrm{in}, F, j}}$.

For example, when assessing a power cycle, the first-law efficiency is the quotient of the net work done by the cycle and the heat input to the cycle. As a consequence of the first law of thermodynamics, we usually get $0<\eta_{1}<1$ (e.g., a natural gas power plant operating at $40 \%$ efficiency), and $0<\eta_{2}<1$ (e.g., an electric motor that is $95 \%$ efficient). However, energy efficiency is not uniform for all energy uses and devices, so nothing physically prevents first-law efficiencies greater than unity (Serrenho et al. 2016). For instance, a typical heat pump has a Coefficient of Performance corresponding to $\eta_{2}$, of 3 and under ideal conditions it can approach 10. This is because the relevant energy input does not include the heat input from the environment (the cold reservoir). Since the domain of $\eta$ is any positive real

\footnotetext{
11 In practice there are heat losses when converting, for example, kinetic energy into mechanical work, but they are unknown a priori. Thus, one can decide to consider an efficiency of 1 which is the theoretical maximum given by the first law of thermodynamics, which means that there is no theoretical thermodynamic result that sets a maximum conversion efficiency in this case. Therefore, we consider electricity as 'pure work' (Serrenho et al. 2016).
}

\footnotetext{
12 It is important not to confuse useful energy with energy services. As put by Cullen and Allwood (2010), energy services (transport of passengers and goods, space heating, and illumination) are the outcomes of the interaction of useful energies (mechanical drive, heat, and light) with passive devices/infrastructures. Hence, all useful energy flows are measured in joules, whereas energy services take different units of measurement such as passenger-km or tonne-km for transport, and lumen for illumination.
} 


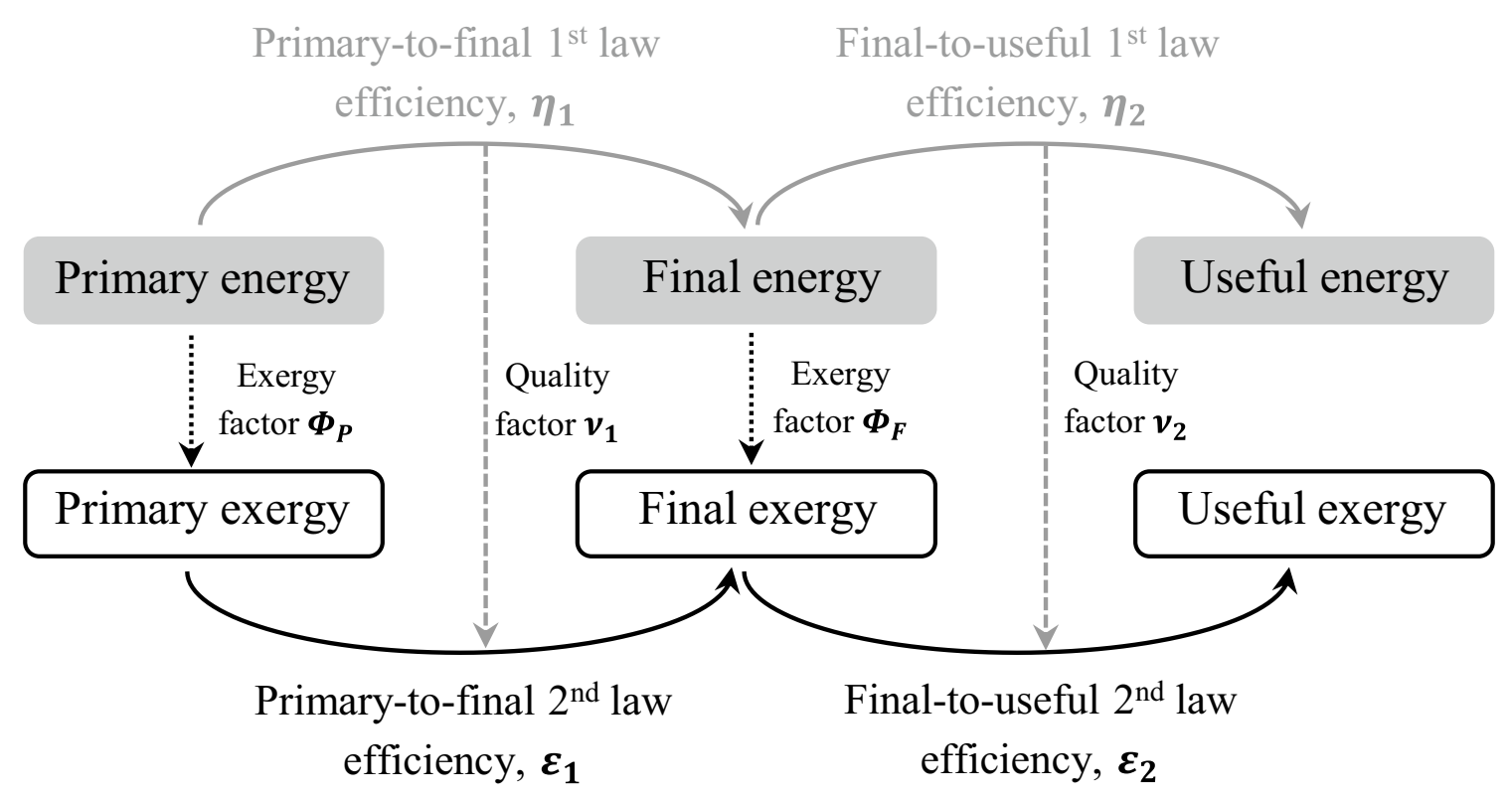

Fig. 8 Energy versus exergy conversion efficiency. Source adapted from Palma et al. (2016)

number, this example demonstrates that the first-law efficiency does not provide a comparable figure of merit across energy uses because it does not take into account the quality of energy flows - electricity and mechanical work are more valuable energy carriers than low temperature heat (Cullen and Allwood 2010).

Exergy efficiency, also called second-law conversion efficiency, provides a more equitable measure of conversion efficiency. It uses mechanical work rather than energy as the basis for comparing devices both to each other and the thermodynamic ideal. For any $j$ primary-to-final process and any $k$ final-to-useful device, exergy efficiencies are respectively defined as:

$\varepsilon_{1, j}=\frac{\text { final exergy output, } j}{\text { primary exergy input, } i}=\frac{E x_{\mathrm{out}, F, j}}{E x_{\mathrm{in}, P, i}}$

and,

$\varepsilon_{2, k}=\frac{\text { useful exergy output, } k}{\text { final exergy input, } j}=\frac{E x_{\text {out }, U, k}}{E x_{\text {in }, F, j}}$.

As a consequence of the second law of thermodynamics, exergy efficiency is always bounded by unity, meaning that the theoretical maximum exergy efficiency of a process is, by definition, always 100\% (Sousa et al. 2017). Therefore the second-law efficiency expresses a figure of the quality and closeness to an ideal process for a given energy use. Exergy efficiency can be calculated directly, by finding the ratio of the output to input exergy flows through the device; in practice this is a much more complicated process. Instead, if the conventional energy efficiency $\eta_{1}$ (respectively $\eta_{2}$ ) is known, then the exergy efficiency $\varepsilon_{1}$ (respectively $\varepsilon_{2}$ ) can be estimated using:

$\varepsilon_{1}=\eta_{1} \times v_{1}$

and,

$\varepsilon_{2}=\eta_{2} \times v_{2}$.

where a dimensionless quality factor $v_{1}$ (respectively $v_{2}$ ) is used to correct for the loss of energy quality (i.e., exergy destruction) in the conversion process (Cullen and Allwood 2010). Even though they logically evolve over time thanks to technical change, Table 3 give typical values for $\eta_{1}, v_{1}$, and $\varepsilon_{1}$ of primary-to-useful processes, while Table 4 gives typical values for $\eta_{2}, v_{2}$, and $\varepsilon_{2}$ of end-use conversion devices. Figure 8 summarizes the interrelations of all variables defined in the present section.

Finally, considering that $j$ final carriers deliver end-use services through $k$ devices, one can compute the quantity-weighted average energy and exergy efficiency of all $j$ primary-to-final processes $\left(\eta_{1}\right.$, respectively $\left.\varepsilon_{1}\right)$, and the quantity-weighted average energy and exergy efficiency of all $k$ final-to-useful devices $\left(\eta_{2}\right.$, respectively $\left.\varepsilon_{2}\right)$, and finally obtain the energy and exergy aggregate efficiency for the whole economy ( $\eta$, respectively $\varepsilon$ ):

$\eta=\eta_{1} \eta_{2}=\frac{\sum_{j} \eta_{1, j} E_{\mathrm{out}, F, j}}{\sum_{j} E_{\mathrm{out}, F, j}} \frac{\sum_{k} \eta_{2, k} E_{\mathrm{out}, U, k}}{\sum_{k} E_{\mathrm{out}, U, k}}$ 
Table 3 Energy and exergy efficiency of primary-to-final conversion processes

\begin{tabular}{llll}
\hline P-to-F process & Description & $\eta_{1}(\%)$ & $v_{1}(\%)$ \\
\hline Electricity generation from & & $\varepsilon_{1}(\%)$ \\
Coal & Hard coal, lignite and derived fuels (e.g., coke, blast furnace gas) & 34 & 94 \\
Oil & Crude oil and petroleum products & 37 & 94 \\
Gas & Natural gas and gas works & 40 & 96 \\
Nuclear & Nuclear fission (heat equivalent of electricity) & 33 & 100 \\
Biomass & Combustible plant/animal products and municipal/industrial waste & 25 & 90 \\
Renewable & Hydro, geothermal, solar, wind, tide, and wave energy & 80 & 35 \\
Fuel transformation & In petroleum refineries, gas works, coal preparation, liquefaction, distribu- & 93 & 100 \\
& tion and own-use & 53 & 100 \\
CHP & Combined heat and power plants (all fuels) & 56 & 93 \\
Heat & Utility heat plants (all fuels) & 85 & 62 \\
\hline
\end{tabular}

By definition, the different $v_{1}$ are the inverse of the primary $\left(\Phi_{P}\right)$ or final $\left(\Phi_{F}\right)$ exergy factors of Table 1

Source Cullen and Allwood (2010)

Table 4 Energy and exergy efficiency of final-to-useful conversion devices

\begin{tabular}{|c|c|c|c|c|}
\hline F-to-U device & Description & $\eta_{2}(\%)$ & $v_{2}(\%)$ & $\varepsilon_{2}(\%)$ \\
\hline \multicolumn{5}{|l|}{ Motion } \\
\hline Diesel engine & Compression ignition diesel engine: truck, car, ship, train, generator & 22 & 95 & 21 \\
\hline Petrol engine & Spark ignition petrol engine: car, generator, garden machinery & 13 & 99 & 12 \\
\hline Aircraft engine & Turbofan, turboprop engine & 28 & 99 & 27 \\
\hline Other engine & Steam or natural gas powered engine & 47 & 53 & 25 \\
\hline Electric motor & AC/DC induction motor (e.g., refrigeration) & 60 & 93 & 56 \\
\hline \multicolumn{5}{|l|}{ Heat } \\
\hline Oil burner & Boiler, petrochemical cracker, chemical reactor & 61 & 25 & 15 \\
\hline Biomass burner & Open fire/stove, boiler & 34 & 20 & 7 \\
\hline Gas burner & Open fire/stove, boiler, chemical reactor & 64 & 21 & 13 \\
\hline Coal burner & Open fire/stove, boiler, blast furnace, chemical reactor & 59 & 31 & 19 \\
\hline Electric heater & Electric resistance heater, electric arc furnace & 80 & 30 & 24 \\
\hline Heat exchanger & District heat, heat from CHP & 87 & 15 & 24 \\
\hline \multicolumn{5}{|l|}{ Other } \\
\hline Cooler & Refrigeration, air con: industry, commercial, residential & 104 & 6 & 7 \\
\hline Light device & Lighting: tungsten, fluorescent, halogen & 13 & 90 & 12 \\
\hline Electronic & Computers, televisions, portable devices & 20 & 30 & 6 \\
\hline
\end{tabular}

Source Cullen and Allwood (2010)

and,

$\varepsilon=\varepsilon_{1} \varepsilon_{2}=\frac{\sum_{j} \varepsilon_{1, j} E x_{\mathrm{out}, F, j}}{\sum_{j} E x_{\mathrm{out}, F, j}} \frac{\sum_{k} \varepsilon_{2, k} E x_{\mathrm{out}, U, k}}{\sum_{k} E x_{\mathrm{out}, U, k}}$.

\section{References}

Arvesen A, Hertwich EG (2015) More caution is needed when using life cycle assessment to determine energy return on investment (EROI). Energy Policy 76:1-6
Ayres RU (1998) Eco-thermodynamics: economics and the second law. Ecol Econ 26:189-209

Bolt J, Inklaar R, de Jong H, van Zanden JL (2018) Maddison Project Database 2018. https://www.rug.nl/ggdc/historicaldevelopment/ maddison/releases/maddison-project-database-2018. Accessed 12 Apr 2018

Brandt AR, Dale M, Barnhart CJ (2013) Calculating systems-scale energy efficiency and net energy returns: a bottom-up matrixbased approach. Energy 62:235-247

Broberg T, Berg C, Samakovlis E (2015) The economy-wide rebound effect from improved energy efficiency in Swedish industries-A general equilibrium analysis. Energy Policy 83:26-37

Brockway P, Saunders H, Heun M, Foxon T, Steinberger J, Barrett J, Sorrell S (2017) Energy rebound as a potential threat to a 
low-carbon future: findings from a new exergy-based nationallevel rebound approach. Energies 10(1):51

Brockway P, Sorrell S, Foxon T, Miller J (2018) Exergy economics : new insights into energy consumption and economic growth. In: Jenkins KEH, Hopkins D (eds) Transitions in energy efficiency and demand: the emergence, diffusion and impact of low-carbon innovation. Routledge, London, pp 133-155 chapter 8

Brockway PE, Barrett JR, Foxon TJ, Steinberger JK (2014) Divergence of trends in US and UK aggregate exergy efficiencies 1960-2010. Environ Sci Technol 48(16):9874-9881

Brockway PE, Owen A, Brand-Correa LI, Hardt L (2019) Estimation of global final stage energy return-on-investment for fossil fuels with comparison to renewable energy sources. Nature Energy (in press)

Brockway PE, Steinberger JK, Barrett JR, Foxon TJ (2015) Understanding China's past and future energy demand: An exergy efficiency and decomposition analysis. Appl Energy 155:892-903

Bye B, Fæhn T, Rosnes O (2018) Residential energy efficiency policies: costs, emissions and rebound effects. Energy 143:191-201

Court V, Fizaine F (2017) Long-term estimates of the energy-returnon-investment (EROI) of coal, oil, and gas global productions. Ecol Econom 138:145-159

Cullen JM, Allwood JM (2010) Theoretical efficiency limits for energy conversion devices. Energy 35(5):2059-2069

De Stercke S (2014) Dynamics of energy systems: a useful perspective. Technical report, International Institute for Applied Systems Analysis (IR-14-013), Schloss Laxenburg, AT

Debeir J-C, Deleage J-P, Hemery D (1991) In the servitude of power: energy and civilisation through the ages. Zed Books, London

Debeir J-C, Deleage J-P, Hemery D (2013) Une Histoire de l'Énergie : Les Servitudes de la Puissance, 2nd edn. Flammarion, Paris

Dupont E, Koppelaar R, Jeanmart H (2018) Global available wind energy with physical and energy return on investment constraints. Appl Energy 209:322-338

Eisenmenger N, Warr B, Magerl A (2017) Trends in Austrian resource efficiency: an exergy and useful work analysis in comparison to material use, $\mathrm{CO} 2$ emissions, and land use. J Ind Ecol 21(5):1250-1261

Feng J, Feng L, Wang J, King CW (2018) Modeling the point of use EROI and its implications for economic growth in China. Energy 144:232-242

Fizaine F, Court V (2016) Energy expenditure, economic growth, and the minimum EROI of society. Energy Policy 95:172-186

Gordon RJ (2015) Secular stagnation: a supply-side view. Am Econ Rev 105(5):54-59

Hall CA (2017) Will EROI be the primary determinant of our economic future? The view of the natural scientist versus the economist. Joule 1(4):635-638

Hall CA, Lambert JG, Balogh SB (2014) EROI of different fuels and the implications for society. Energy Policy 64:141-152

Hall CAS, Balogh S, Murphy DJ (2009) What is the minimum EROI that a sustainable society must have? Energies 2(1):25-47

Heun MK, Brockway P (2019) Meeting 2030 primary energy and economic growth goals: mission impossible? Appl Energy 251:112697

King C, Maxwell J, Donovan A (2015) Comparing world economic and net energy metrics, part 1: single technology and commodity perspective. Energies 8(12):12949-12974
King CW (2014) Matrix method for comparing system and individual energy return ratios when considering an energy transition. Energy 72:254-265

King LC, van den Bergh JCJM (2018) Implications of net energyreturn-on-investment for a low-carbon energy transition. Nat Energy 3(4):334-340

Kümmel R (2011) The second law of economics: energy, entropy, and the origins of wealth. Springer, New York, NY

Lambert JG, Hall CA, Balogh S, Gupta A, Arnold M (2014) Energy, EROI and quality of life. Energy Policy 64:153-167

Masnadi MS, El-Houjeiri HM, Schunack D, Li Y, Roberts SO, Przesmitzki S, Brandt AR, Wang M (2018) Well-to-refinery emissions and net-energy analysis of China-s crude-oil supply. Nat Energy 3(3):220-226

Miller J, Foxon T, Sorrell S (2016) Exergy accounting: a quantitative comparison of methods and implications for energy-economy analysis. Energies 9(12):947

Modahl IS, Raadal HL, Gagnon L, Bakken TH (2013) How methodological issues affect the energy indicator results for different electricity generation technologies. Energy Policy 63:283-299

Murphy DJ, Hall CA, Dale M, Cleveland C (2011) Order from chaos: a preliminary protocol for determining the EROI of fuels. Sustainability 3(10): 1888-1907

Palma M, Sousa T, Guevara Z (2016) How much detail should we use to compute societal aggregated exergy efficiencies? Energies 9(12):364

Sciubba E (2011) What did Lotka really say? A critical reassessment of the 'maximum power principle'. Ecol Modell 222(8):1347-1353

Serrenho AC, Sousa T, Warr B, Ayres RU, Domingos T (2014) Decomposition of useful work intensity: the EU (European Union)-15 countries from 1960 to 2009. Energy 76:704-715

Serrenho AC, Warr B, Sousa T, Ayres RU, Domingos T (2016) Structure and dynamics of useful work along the agriculture-industryservices transition: Portugal from 1856 to 2009. Struct Change Econ Dyn 36:1-21

Smil V (2017) Energy and civilization: a history. MIT Press, Cambridge

Sousa T, Brockway PE, Cullen JM, Henriques ST, Miller J, Serrenho AC, Domingos T (2017) The need for robust, consistent methods in societal exergy accounting. Ecol Econ 141:11-21

Summers LH (2015) Demand side secular stagnation. Am Econ Rev 105(5):60-65

Warr B, Ayres R, Eisenmenger N, Krausmann F, Schandl H (2010) Energy use and economic development: a comparative analysis of useful work supply in Austria, Japan, the United Kingdom and the US during 100 years of economic growth. Ecol Econ 69(10):1904-1917

Weißbach D, Ruprecht G, Huke A, Czerski K, Gottlieb S, Hussein A (2013) Energy intensities, EROIs (energy returned on invested), and energy payback times of electricity generating power plants. Energy 52:210-221

Zhang Y, Colosi LM (2013) Practical ambiguities during calculation of energy ratios and their impacts on life cycle assessment calculations. Energy Policy 57:630-633

Publisher's Note Springer Nature remains neutral with regard to jurisdictional claims in published maps and institutional affiliations. 